\title{
High Performance Large-Area Perovskite Solar Cells Enabled by Confined Space Sublimation
}

\author{
Leilei $\mathrm{Gu}^{\dagger}, \S$, Shubo Wang ${ }^{\dagger,}$, Xiang Fang \\ $†$ School of Materials Science and Engineering, Jiangsu Collaborative Innovation Center for Photovoltaic Science and \\ Engineering, Jiangsu Province Cultivation base for State Key Laboratory of Photovoltaic Science and Technology, \\ Changzhou University, Changzhou 213164, China.
}

\$ Micro/Nano Science and Technology Center, Jiangsu University, Zhenjiang 212013, China.

$\S$ These authors contributed equally to this work.

*E-mail: nyyuan@cczu.edu.cn. (Ningyi Yuan)

*E-mail: dingjn@ujs.edu.cn. (Jianning Ding)

Figure S1-S15, showing the schematic of the perovskite device architecture, XRD patterns of perovskite films fabricated by $\mathrm{PbI}_{2}, \mathrm{PbBr}_{2}$, or $\mathrm{PbCl}_{2}$, normalized $\mathrm{PL}$ spectra and bandgap change trend of perovskite films fabricated by $\mathrm{PbBr}_{2}, J-V$ characteristics of devices based on pure $\mathrm{PbX}_{2}$, schematic diagram of the reaction mechanisms, XRD patterns, UV-vis absorption, normalized PL spectra, photographs and SEM images of perovskite films fabricated by substrate A and B, EDS measurement, XPS characterization, bandgap patterns and statistical analyze of the grain size of the perovskite films, statistics of the photovoltaic parameters, Long-term stability and thermal stability results of PSCs, Statistics of the photovoltaic parameters of perovskite solar modules on large-area substrates. Table S1-S3 showing the statistics of the photovoltaic parameters of high-efficiency and wide-band gap PSCs, atomic content of each component in the film before and after the reaction with substrates A and B, performance parameters of the champion perovskite solar modules. 

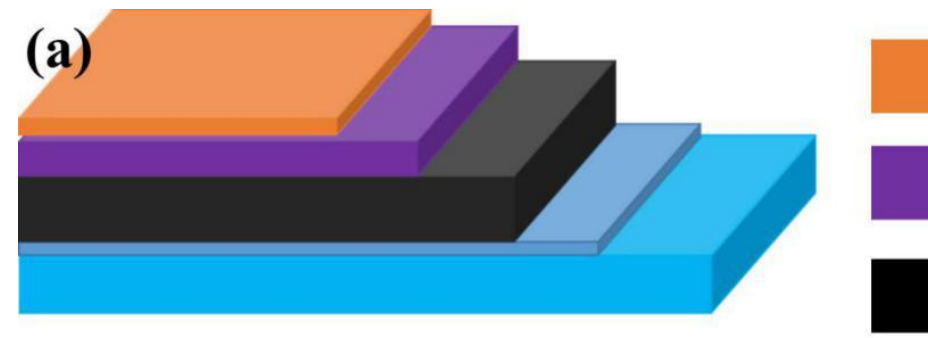

Au

\section{Spiro-MeOTAD}

Perovskite

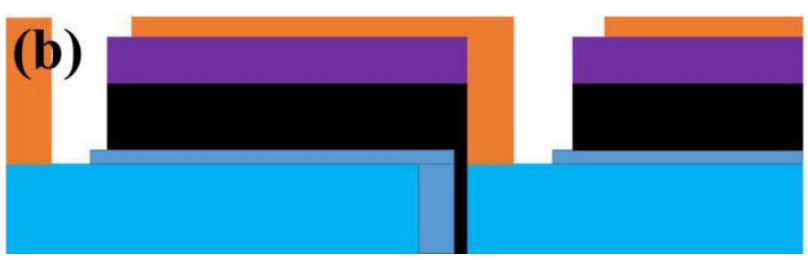

$\mathrm{TiO}_{2}$

\section{FTO-glass}

Figure S1. Schematic of the device architecture of the (a) the small-area PSCs $\left(0.07 \mathrm{~cm}^{2}\right)$ and (b) large-area perovskite solar modules $\left(4 \times 4 \mathrm{~cm}^{2}\right)$.
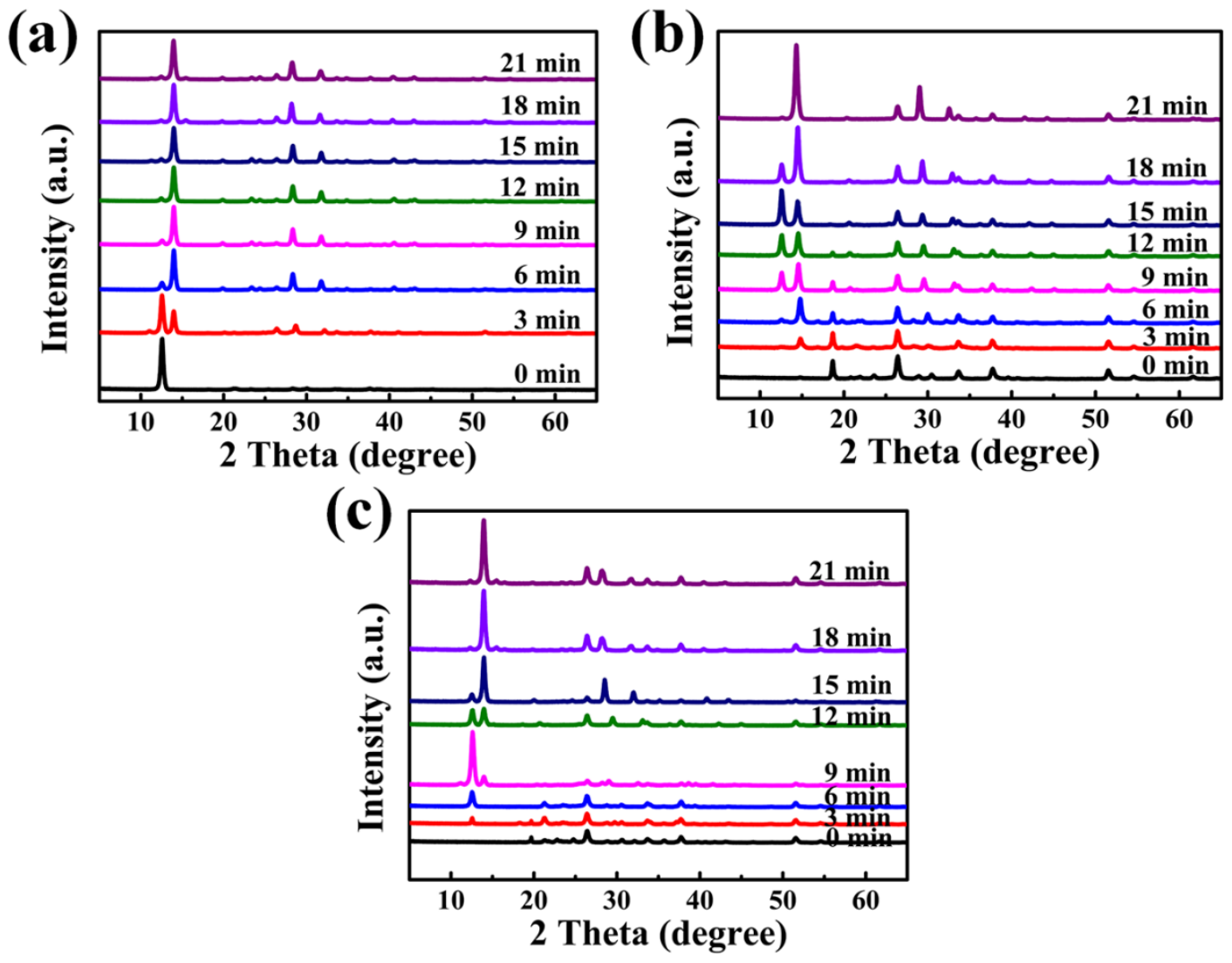

Figure S2. XRD patterns ( $5^{\circ}-65^{\circ}$ ) of films fabricated by sublimating $\mathrm{CH}_{3} \mathrm{NH}_{3} \mathrm{I}$ onto (a) $\mathrm{PbI}_{2}$, (b) $\mathrm{PbBr}_{2}$, or (c) $\mathrm{PbCl}_{2}$ for different reaction durations. 
(a)

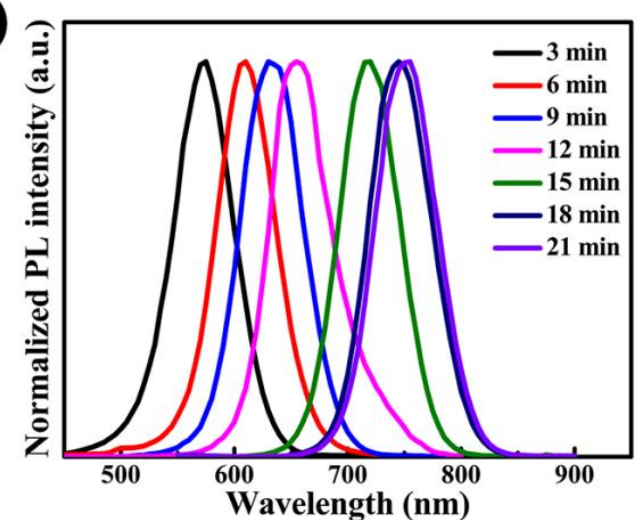

(b)

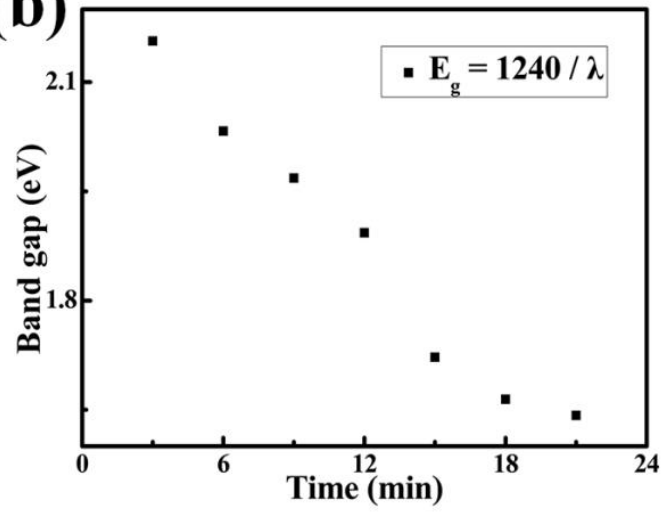

Figure S3. Normalized PL spectra (a) and bandgap change trend (b) of films fabricated by sublimating $\mathrm{CH}_{3} \mathrm{NH}_{3} \mathrm{I}$ onto $\mathrm{PbBr}_{2}$, for different reaction durations.

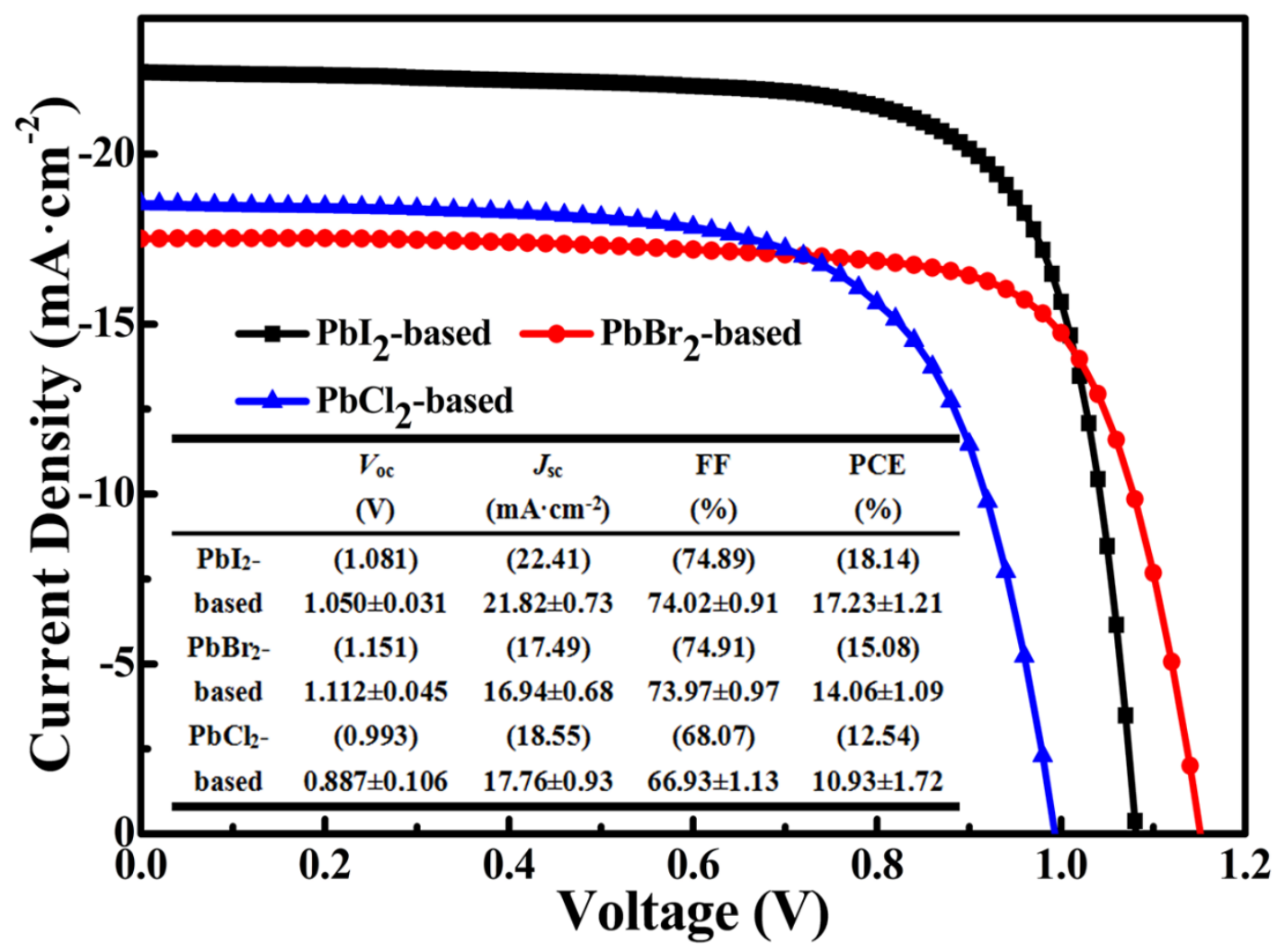

Figure S4. $J-V$ characteristics of devices based on pure $\mathrm{PbX}_{2}$. 
$\mathrm{PbI}_{2}: \quad \mathrm{PbI}_{2} \stackrel{\mathrm{MAI}}{\longrightarrow} \mathrm{MAPbI}_{3}$

$\mathrm{PbBr}_{2}: \mathrm{PbBr}_{2} \stackrel{M A I}{\longrightarrow} \mathrm{MAPbBr}_{x} I_{y}+\mathrm{PbI}_{2}+\mathrm{MABr} \uparrow$

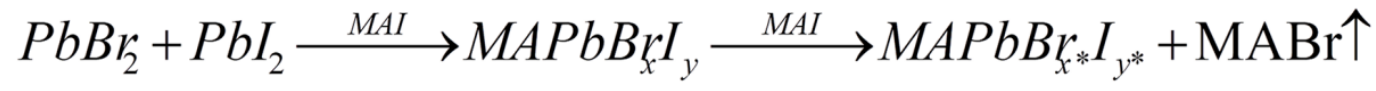

$\mathrm{PbCl}_{2}: \quad \mathrm{PbCl} \stackrel{M A I}{\longrightarrow} M A C \uparrow \uparrow+\mathrm{PbI}_{2}$

$$
\mathrm{PbCl}_{2}+\mathrm{PbI}_{2} \stackrel{\mathrm{MAI}}{\longrightarrow} \mathrm{MAPbCl} \mathrm{I}_{y} \stackrel{\mathrm{MAI}}{\longrightarrow} \mathrm{MAPbI}_{3}+\mathrm{MACl} \uparrow
$$

Figure S5. Schematic diagram of the reaction mechanisms of the three substrates $\mathrm{PbI}_{2}, \mathrm{PbBr}_{2}$ and $\mathrm{PbCl}_{2}$ with $\mathrm{CH}_{3} \mathrm{NH}_{3} \mathrm{I}$.
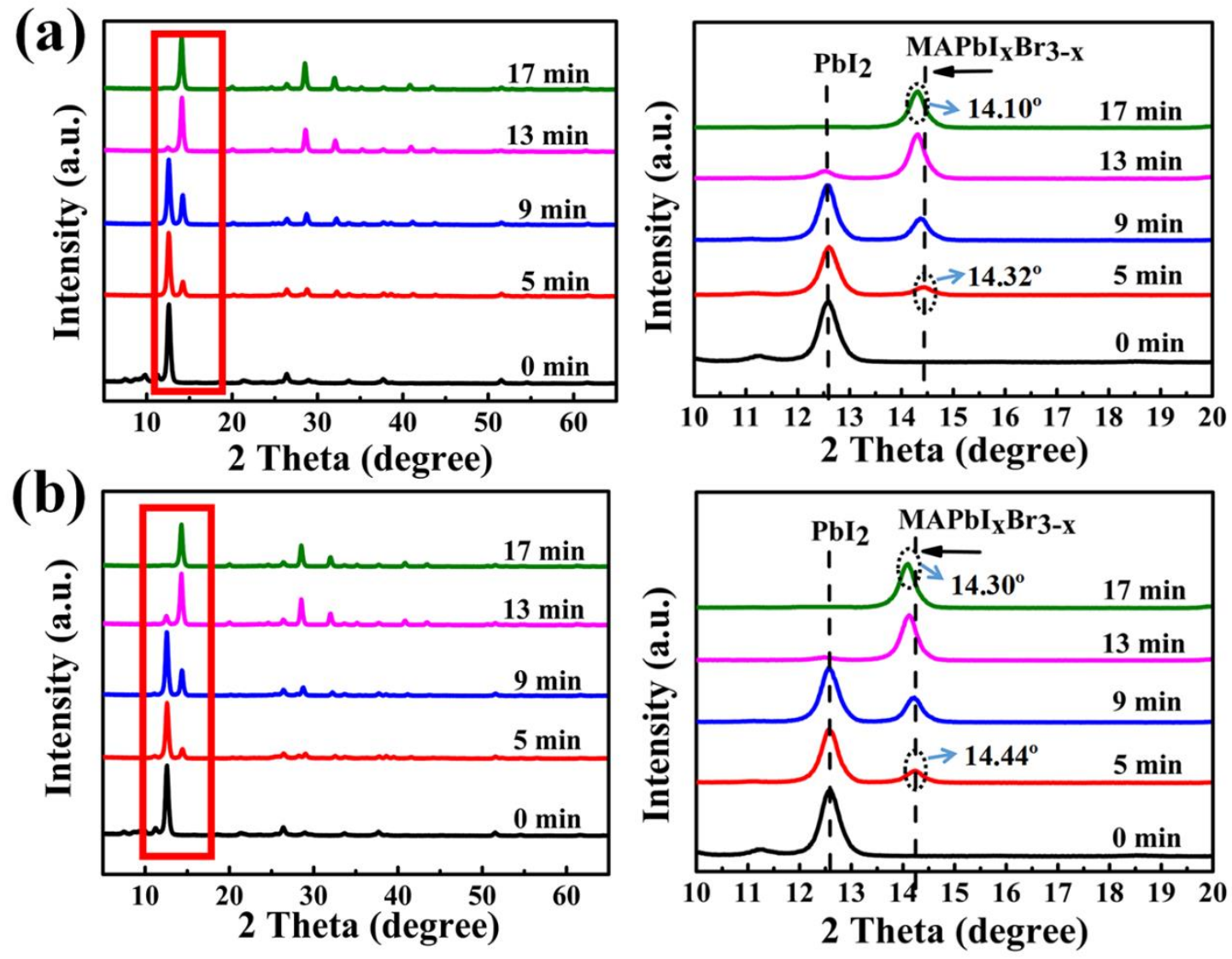

Figure S6. XRD patterns of films fabricated by sublimating $\mathrm{CH}_{3} \mathrm{NH}_{3} \mathrm{I}$ onto (a) substrate A and (b) substrate $\mathrm{B}$. 

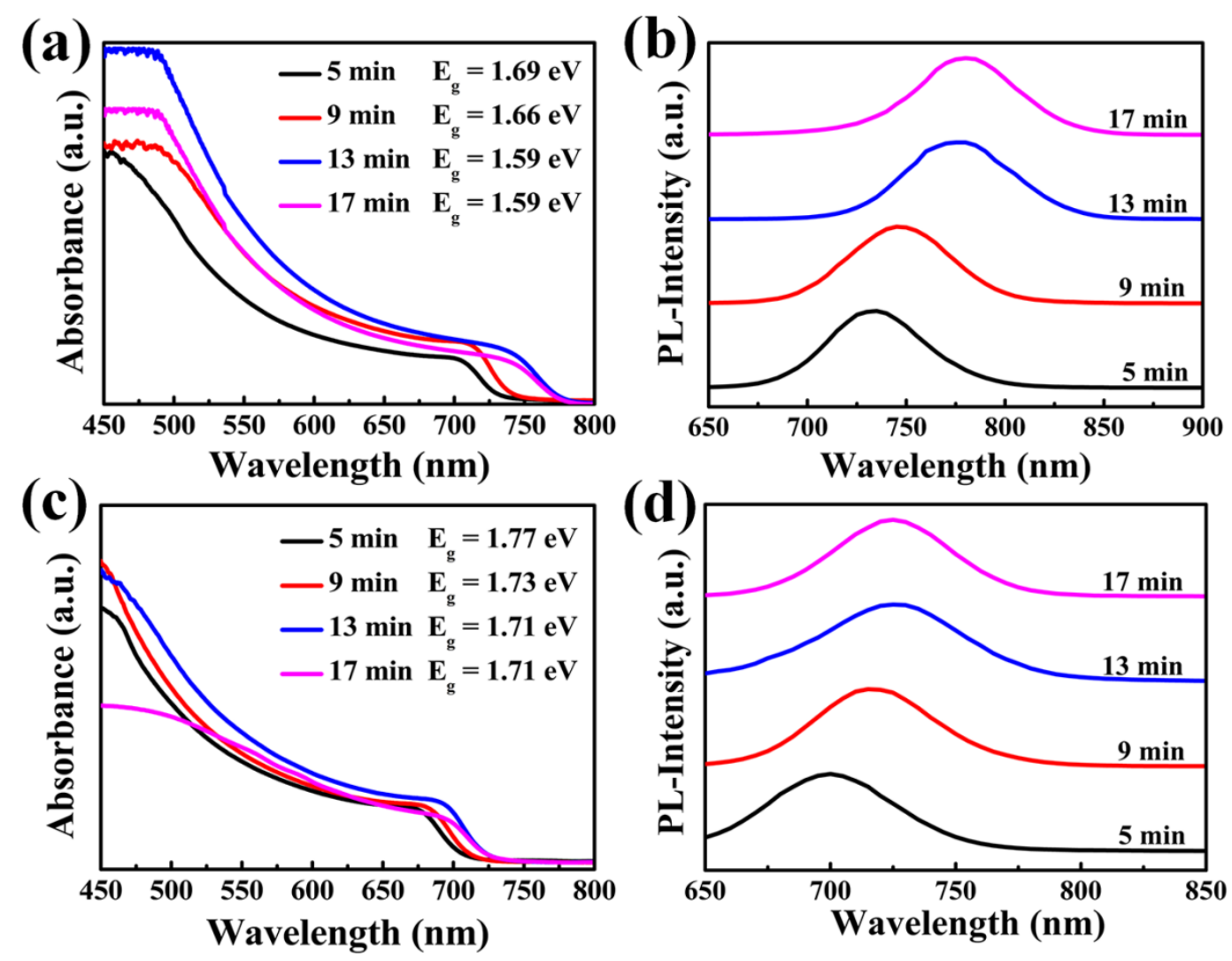

Figure S7. UV-vis absorption and normalized PL spectra of films fabricated by sublimating $\mathrm{CH}_{3} \mathrm{NH}_{3} \mathrm{I}$ onto the two kinds of substrates (a, c)--ansorption spectra of substrates A and B, and (b, d)--normalized PL spectra of substrates A and B.

(a)
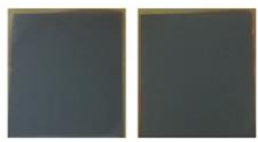

$5 \mathrm{~min}$

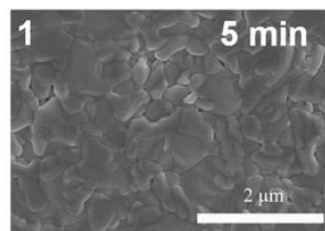

$9 \min$

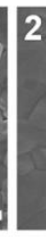

3

$13 \mathrm{~min}$
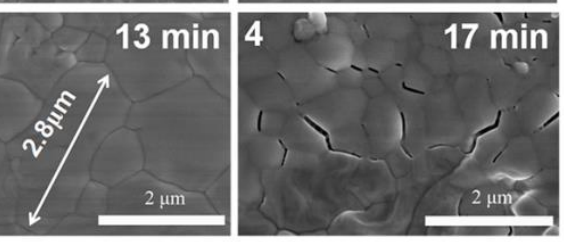

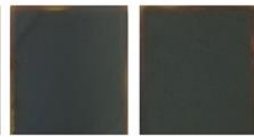

$13 \min 17 \mathrm{~min}$

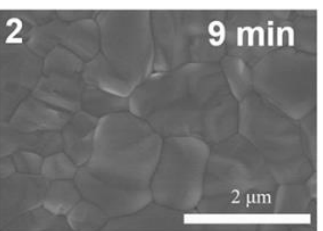

$\min$ (b)

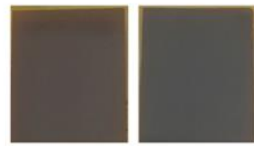

$5 \mathrm{~min}$

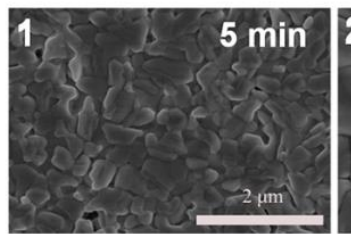

3

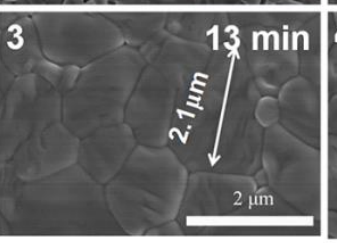

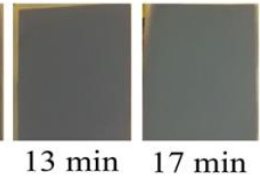
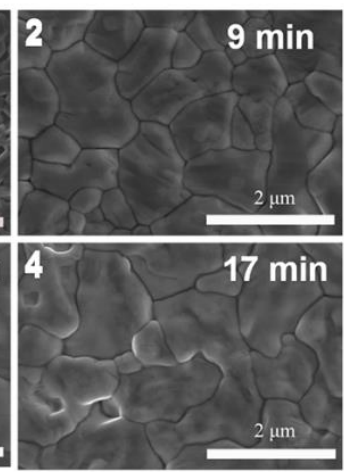

Figure S8. Photographs and SEM images of films fabricated by sublimating $\mathrm{CH}_{3} \mathrm{NH}_{3} \mathrm{I}$ onto the two kinds of substrates, (a)--substrate A, and (b)--substrate B. 


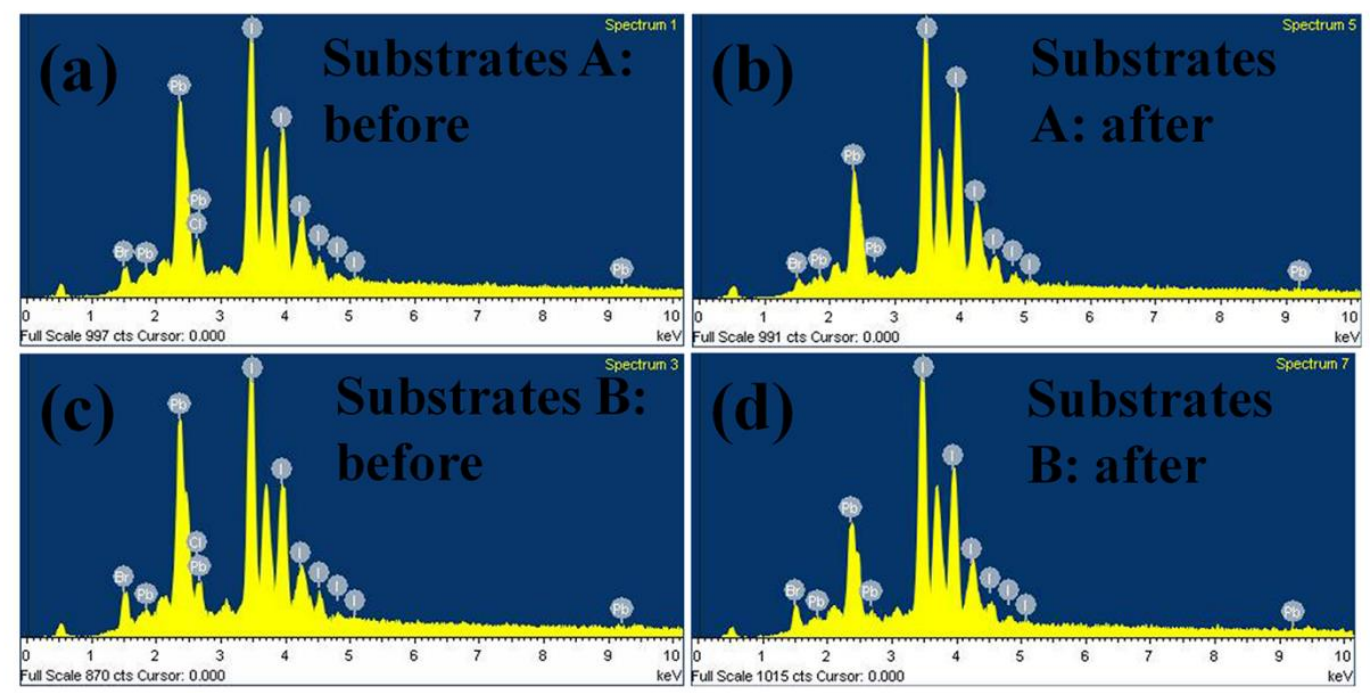

Figure S9. EDS images of the film before (a) and after (b) the reaction with substrates A; EDS images of the film before (c) and after (d) the reaction with substrates B.
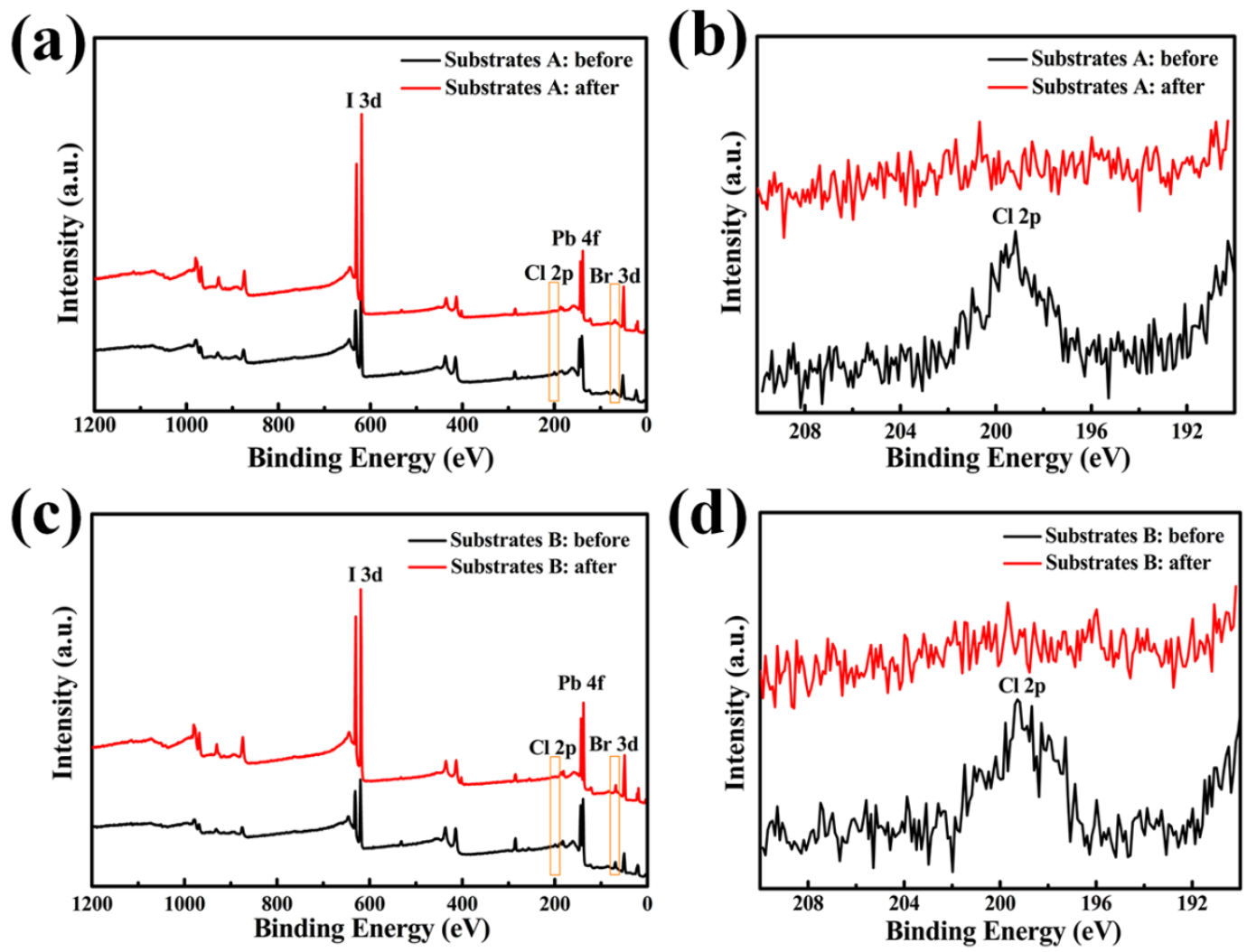

Figure S10. XPS spectra of the film before and after the reaction with substrates A: (a) survey, (b) the high resolution XPS of Cl; XPS spectra of the film before and after the reaction with substrates B: (c) survey, (d) the high resolution XPS of Cl. 


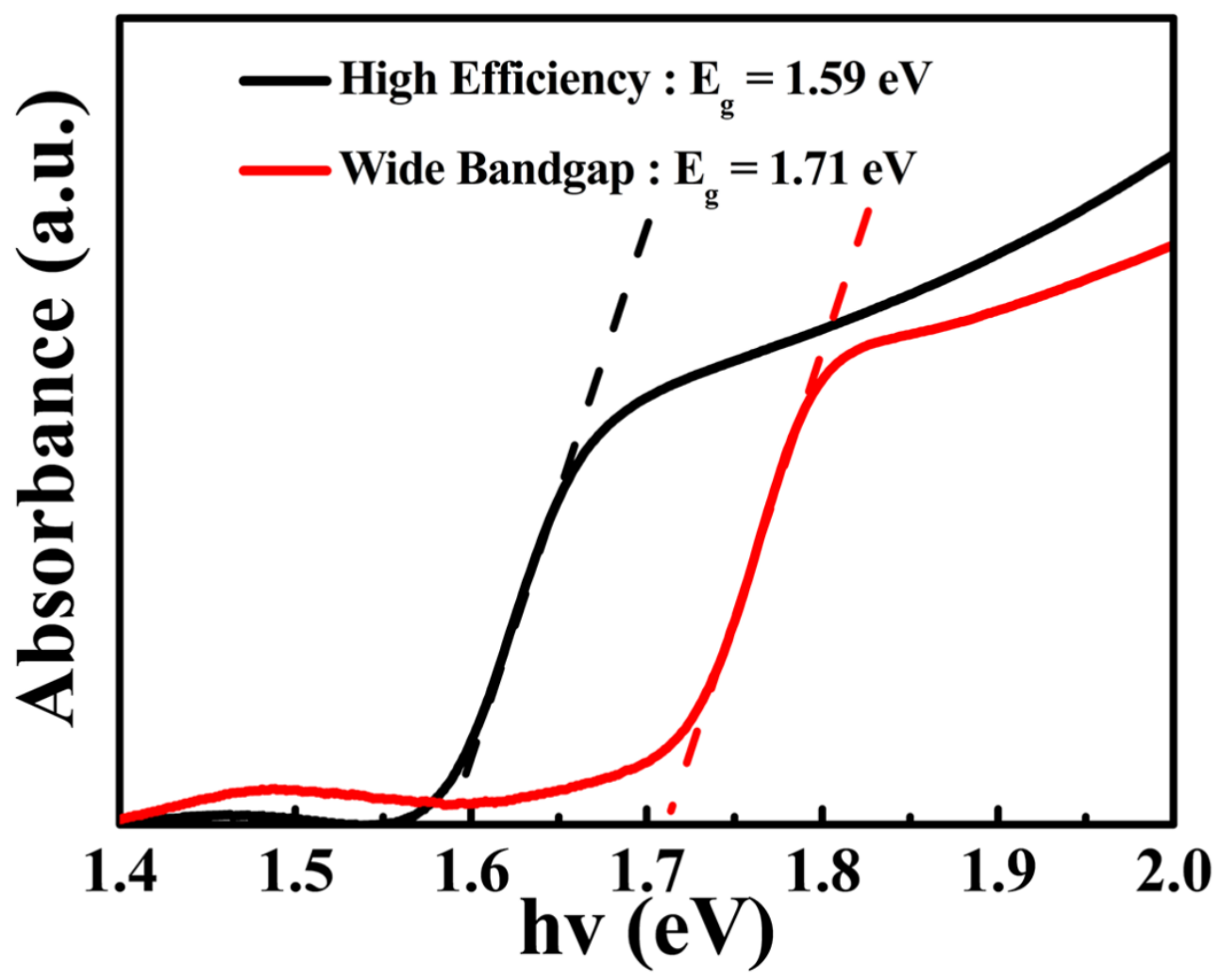

Figure S11. The bandgaps of high-efficiency and wide-bandgap perovskite films
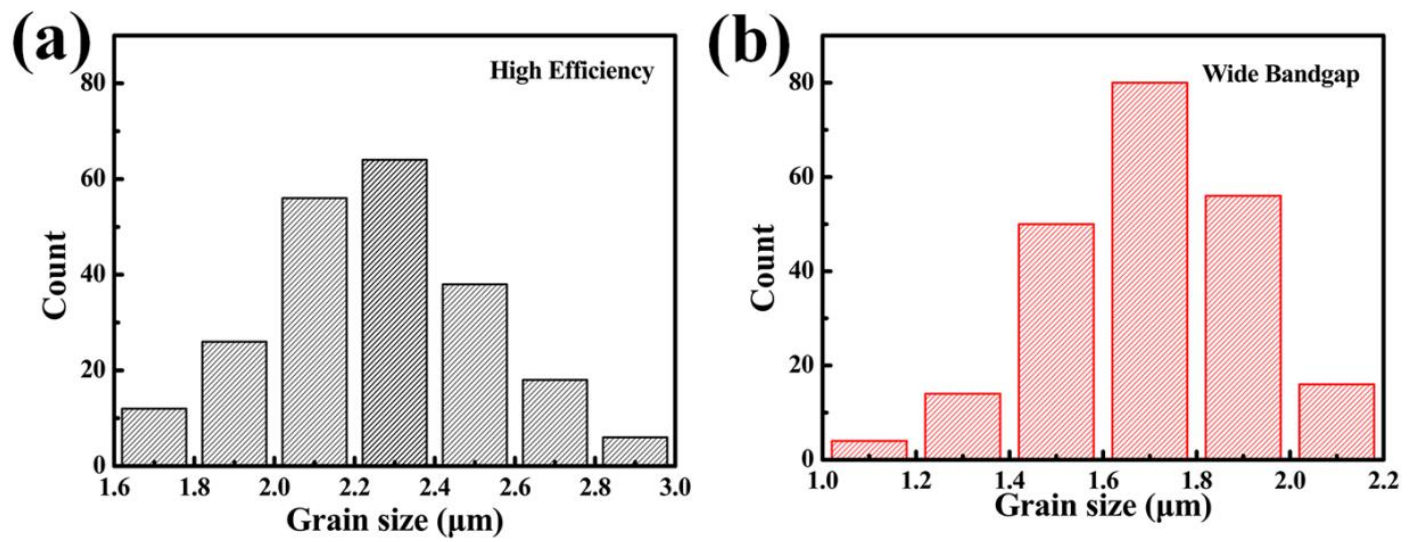

Figure S12. Statistical analyze of the grain size for (a) high-efficiency and (b) wide-bandgap perovskite films. 
(a)

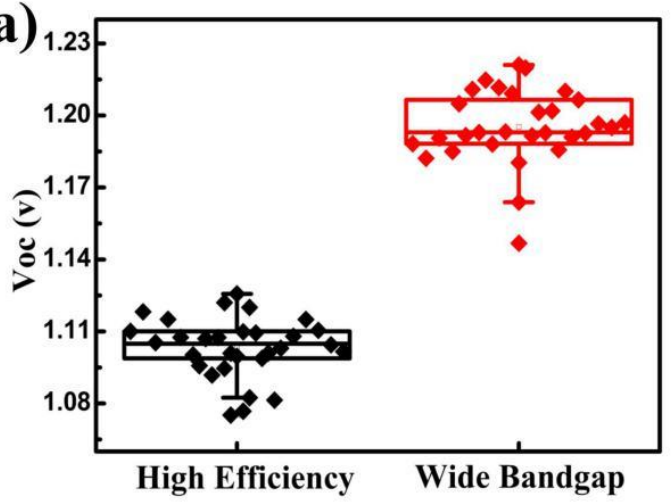

(c)

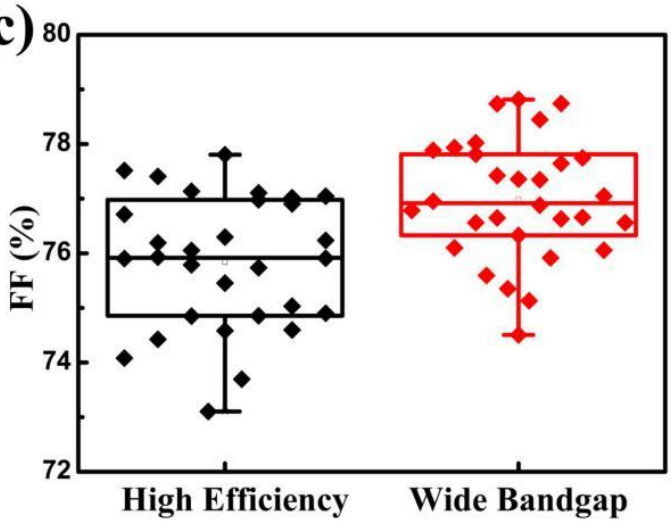

(e)

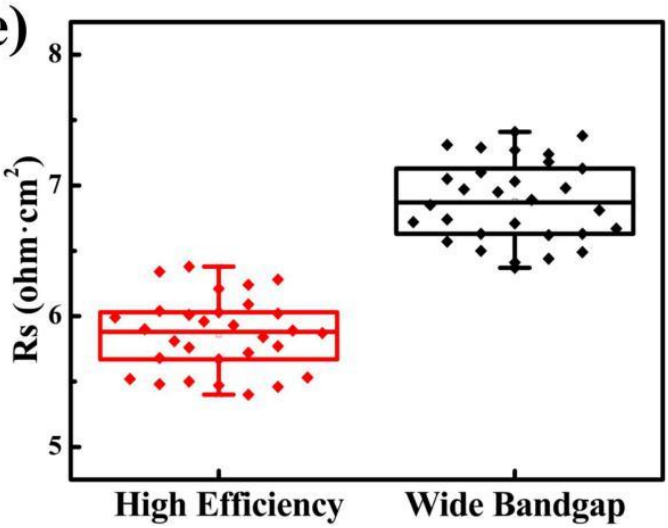

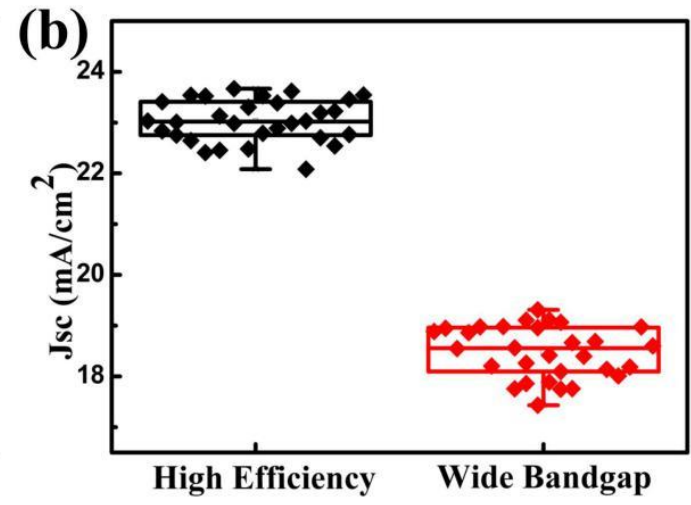

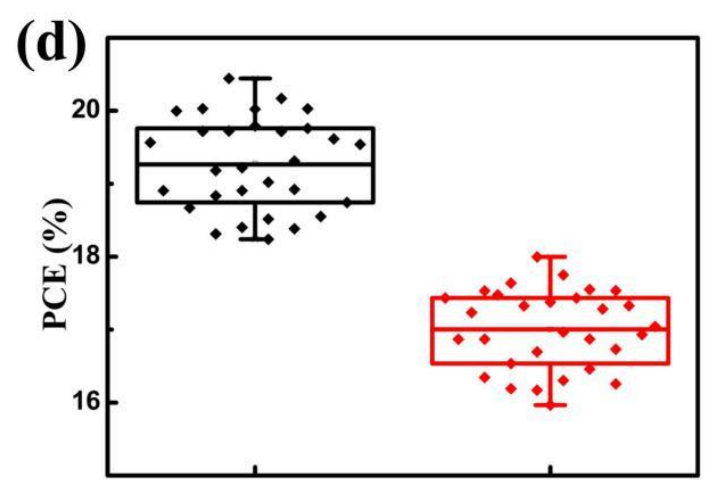

High Efficiency Wide Bandgap

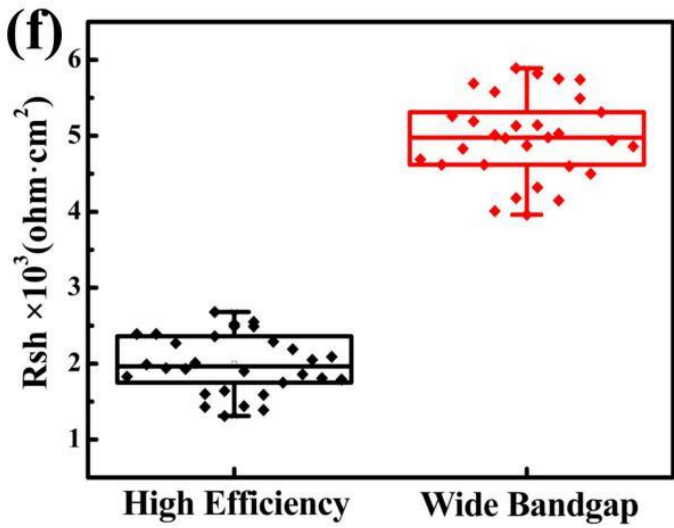

Figure S13. Statistics of the photovoltaic parameters of high-efficiency and wide-bandgap PSCs: (a) $V_{\mathrm{oc}}$, (b) $I_{\mathrm{sc}}$, (c) FF, (d) PCE, (e) Rs, and (f) $R_{\text {sh. }}$.

Table S1. Statistics of the Photovoltaic Parameters of High-Efficiency and Wide-Band Gap PSCs

\begin{tabular}{|c|c|c|c|c|c|c|}
\hline & $\begin{array}{l}V_{o c} \\
(\mathrm{~V})\end{array}$ & $\begin{array}{c}J_{s c} \\
\left(\mathrm{~mA} \cdot \mathrm{cm}^{-2}\right)\end{array}$ & $\begin{array}{l}\mathrm{FF} \\
(\%)\end{array}$ & $\begin{array}{l}\text { PCE } \\
(\%)\end{array}$ & $\begin{array}{c}\mathrm{R}_{\mathrm{s}} \\
\left(\mathrm{ohm} \cdot \mathrm{cm}^{2}\right)\end{array}$ & $\begin{array}{c}\mathrm{R}_{\mathrm{sh}} \times 10^{3} \\
\left(\mathrm{ohm} \cdot \mathrm{cm}^{2}\right)\end{array}$ \\
\hline $\begin{array}{c}\text { High } \\
\text { Efficiency }\end{array}$ & $1.101 \pm 0.025$ & $22.87 \pm 0.80$ & $75.45 \pm 2.35$ & $19.34 \pm 1.11$ & $5.89 \pm 0.49$ & $1.86 \pm 0.82$ \\
\hline $\begin{array}{c}\text { Wide } \\
\text { Bandgap }\end{array}$ & $1.184 \pm 0.037$ & $18.37 \pm 0.94$ & $76.50 \pm 2.11$ & $16.98 \pm 1.01$ & $6.89 \pm 0.52$ & $4.93 \pm 0.97$ \\
\hline
\end{tabular}



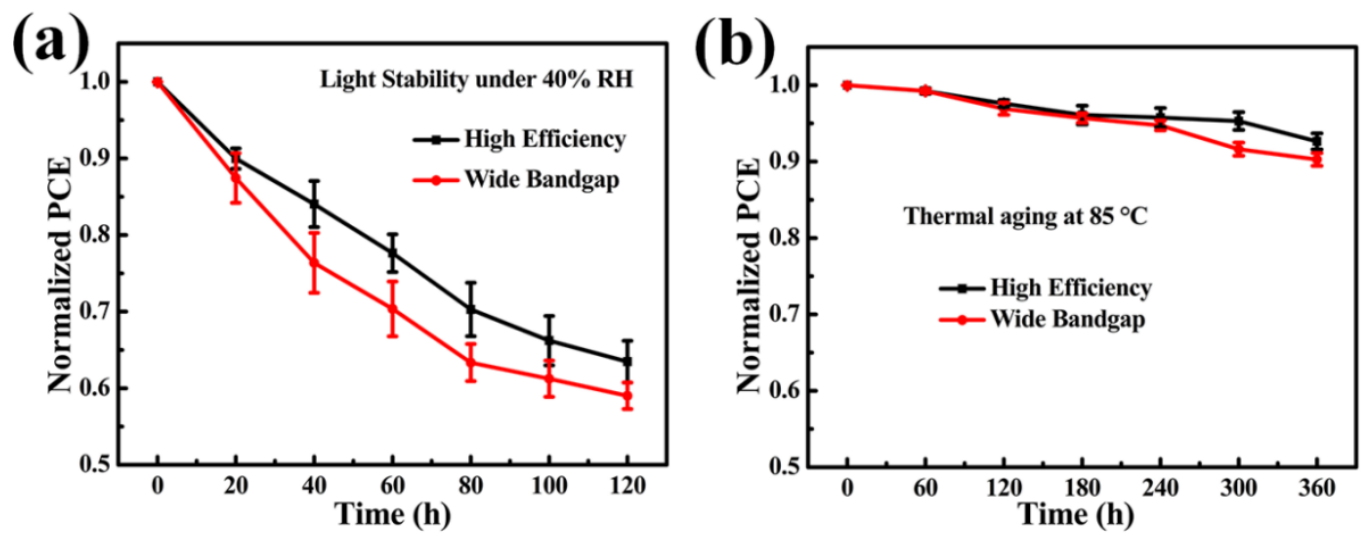

Figure S14. (a) Long-term stability and (b) thermal stability measurements of high-efficiency and wide-bandgap devices without encapsulation.
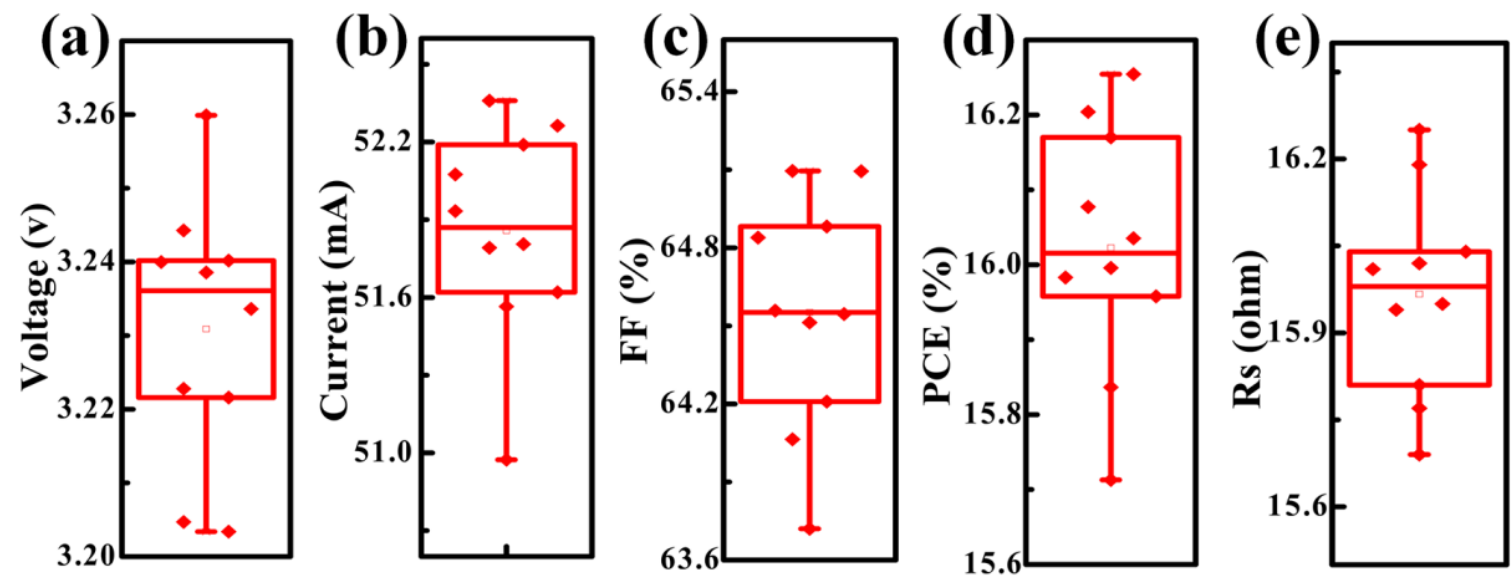

Figure S15. Statistics of the photovoltaic parameters of perovskite solar modules on large-area $\left(4 \times 4 \mathrm{~cm}^{2}\right)$ substrates prepared with confined space sublimation: (a) $V_{\mathrm{oc}}$, (b) $I_{\mathrm{sc}}$, (c) FF, (d) PCE, and (e) $\mathrm{R}_{\mathrm{s}}$.

Table. S2 Atomic Content of each Component in the Film before and after the Reaction with Substrates A and B.

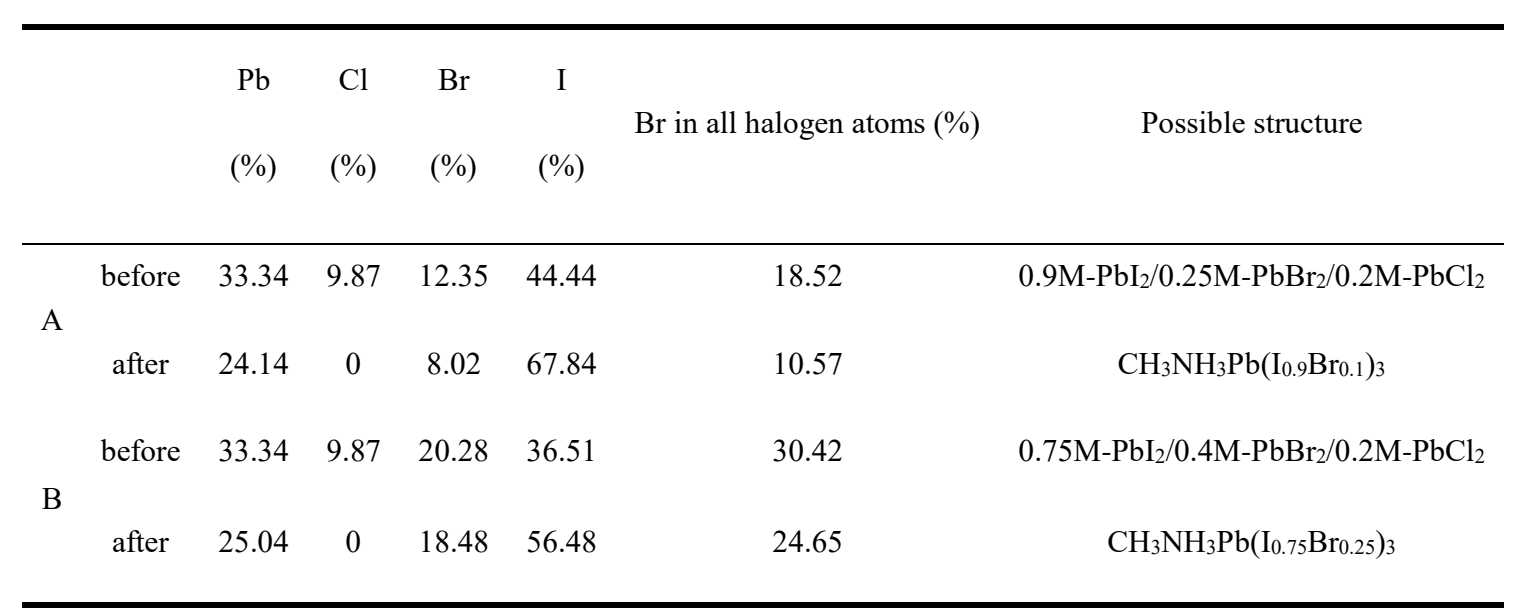


Table S3 Performance Parameters of the Champion Perovskite Solar Modules.

\begin{tabular}{|c|c|c|c|c|c|c|c|}
\hline $\begin{array}{c}\text { Number of cells } \\
\text { in series }\end{array}$ & $\begin{array}{c}\text { Active area } \\
\qquad\left(\mathrm{cm}^{2}\right)\end{array}$ & Scan direction & $\begin{array}{l}V_{\mathrm{oc}} \\
(\mathrm{V})\end{array}$ & $\begin{array}{c}I_{\mathrm{sc}} \\
(\mathrm{mA})\end{array}$ & $\begin{array}{l}\mathrm{FF} \\
(\%)\end{array}$ & $\begin{array}{l}\text { PCE } \\
(\%)\end{array}$ & $\begin{array}{c}\mathrm{R}_{\mathrm{s}} \\
\text { (ohm) }\end{array}$ \\
\hline \multirow{3}{*}{1} & \multirow{3}{*}{2.25} & reverse & 1.076 & 52.31 & 70.68 & 17.68 & 5.51 \\
\hline & & & & & & & \\
\hline & & forward & 1.069 & 52.26 & 69.73 & 17.31 & 5.78 \\
\hline \multirow{3}{*}{2} & \multirow{3}{*}{4.50} & reverse & 2.151 & 52.74 & 66.74 & 16.82 & 11.25 \\
\hline & & & & & & & \\
\hline & & forward & 2.127 & 52.39 & 65.05 & 16.11 & 12.87 \\
\hline \multirow{3}{*}{3} & \multirow{3}{*}{6.75} & reverse & 3.240 & 52.17 & 64.88 & 16.25 & 15.69 \\
\hline & & & & & & & \\
\hline & & forward & 3.181 & 52.11 & 61.66 & 15.14 & 18.41 \\
\hline
\end{tabular}

